Revista de Neuro-Psiquiatría 2003; 66: 335-343

\title{
NEUROGENÉTICA DE LAS FUNCIONES COGNITIVAS
}

\author{
Por EDMUNDO BETETA PACHECO*
}

\begin{abstract}
RESUMEN
Se revisan algunos aspectos de Neurobiología y Neurogenética, destacando las posibles relaciones de los estudios del genoma humano con las funciones cognitivas. En la posibilidad de brindar bases genéticas de la cognición, se examinan 5 grupos de alteraciones del sistema cognitivo en correlación con la anormalidad genética, su localización, la proteína anormal del gen y la función establecida en la ultraestructura neuronal: 1. Retardo mental asociado a una monosomia y trisomia. 2. Desórdenes complejos del sistema cognitivo relacionado a un locus genético cuantitativo. 3. Retardo mental sindrómico, producido por mutaciones de genes con tripletes y anticiparon. 4. Retardo mental no específico vinculado a una proteína anormal de un gen aislado y 5. Las demencias interrelacionadas con el producto proteico de un gen aislado mapeado en diferentes cromosomas. A propósito de los desórdenes neurogenéticos, se discuten las últimas investigaciones en bioquímica molecular que revelan nuevos conceptos en las bases anatómicas fisiológicas y genéticas del sistema cognitivo.
\end{abstract}

\section{ABSTRACT}

General knowledge about human genoma related with cognitive functions is presented. Single gen disorders related with chromosomal abnormalities that produce cognitive disfunction is reviewed: 1. Mental retardation associate to segmental monosomy and trisomy. 2. Cognitive function complex disorder related to quantitative trait locus. 3. Syndromic mental retardation due to single gen mutation. 4. Non-specific mental retardation link to abnormal gen product from single gen. 5. dementias related to abnormal gen product from single gen maped in several chromosomes. The review of advances in neurogenetic and molecular biochemistry show new anatomic, physiologycal and genetic basis of the cognitive system.

Palabras-Clave: Neurogenética, cognición. Funciones cognitivas, sistema cognitivo.

KEY WORDS : Neurogenetic, cognition. Cognitive functions, cognitive system.

\footnotetext{
* Profesor Principal de Medicina, Jefe de LAB. Psicofisiología, Facultad de Medicina y Psicología, UNMSM. Profesor Principal de Medicina y Fisiología, Facultad de Medicina, URP.
} 
La neurogenética ha requerido de la neurobiología para estudiar la genética de los mamíferos, basada en estudios realizados en insectos, nemátodos, peces, anfibios, aves y en huéspedes de otros organismos. La neurogenética o genética molecular, ha tenido en los últimos 30 años un desarrollo extraordinario. Se ha estudiado el programa genético, la localización cromosómica, el secuenciamiento de los genes, la determinación de la función de las proteínas específicas del sistema nervioso, las técnicas de recombinación del DNA, las anormalidades cromosómicas, los aspectos genéticos de las enfermedades hereditarias, los métodos de diagnóstico, el estudio de los modelos animales y la producción de ingeniería genética (McKusick).

En los últimos 16 años, la decodificación de la secuencia del DNA, representa el experimento biológico más importante en un programa internacional, denominado proyecto del genoma humano (Evans). El genoma humano está compuesto por 2 billones de nucleótidos de DNA, organizado en los 23 cromosomas, representando un promedio de 60,000 a 70,000 genes con proteínas codificadas. Estos genes, constituyen sólo el $2-3 \%$ de la secuencia total del DNA, mientras que el $40 \%$ de la secuencia no tiene significado conocido y el $58 \%$ es DNA no codificado, probablemente es responsable de funciones no determinadas o regula la expresión de los genes en los organismos complejos (Gabor-Mikolos, Rubin).

Se han identificado 2,000 genes estructurales, regulatorios activos en el sistema nervioso central (SNC), sin embargo, existen 100,000 genes de los cuales no tenemos información de su contribución en la fun- ción cerebral y en las enfermedades neurológicas. De otro lado, se han encontrado 5,000 enfermedades genéticas, de las cuales sólo se conoce la información de la secuencia genética en 1,000 .

En este artículo de revisión se tratarán las bases moleculares de las funciones cognitivas*.

En el proyecto de la regulación de los genes humanos, deberá demostrarse la expresión de los genes neuronales para producir eventos funcionales diferenciados, en circuitos de miles de neuronas que expliquen la información cognitiva y soporten la conducta humana normal.

En el genoma humano, observemos varios tipos de desórdenes genéticos asociados con disturbios cognitivos, los cuales se han relacionado con diversos genes mapeados en los cromosomas: 1) En algunos casos, la anormalidad corresponde a un gen aislado o un desorden cromosomial que resulta usualmente en un retardo mental. 2) En otros casos, un gen mapeado y luego potencialmente clonado, ha resultado en variaciones de habilidades intelectuales, tales como variantes del cuociente intelectual, alteraciones del lenguaje y dislexia. 3) Por último, la investigación de mutaciones en modelos animales (ratones) ha permitido aproximarnos a las operaciones neuronales y sus conexiones para entender algunos procesos cognitivos como el aprendizaje y la memoria, tal es la codificación de la memoria espacial en el hipocampo (McHugh, Rotenberg y col.). En consecuencia, los efectos genéticos que determinan la función cognitiva son pleiotróficos (efectos múltiples de un gen o un par de genes) y tal vez, poligénicos (determinados por un número

* Incluyen en general, funciones intelectuales y parámetros biológicos de la conducta humana. 
de genes en diferentes locus con pequeños efectos aditivos).

Revisaremos, la taxonomía de J. Flint (Institute of Molecular Medicine, Oxford, Uk) modificada en este estudio, en 5 grupos de etiologías genéticas-bioquímicas (Tabla I) para relacionarlas con variantes clínicas que afectan las funciones cognitivas.

En el primer grupo. Están los pacientes con retardo mental, portadores de una

TABLA I

Desórdenes genéticos asociados a disturbios cognitivos

\begin{tabular}{|c|c|c|c|c|c|c|}
\hline \multicolumn{2}{|r|}{ Síndrome } & Desorden Clínico & Anormal Genética & Locus & Producto Genético & Función \\
\hline 1 & Retardo Mental & $\begin{array}{l}\text { Sínd. Williams } \\
\text { Sínd. Turne } \\
\text { Sínd. Down }\end{array}$ & $\begin{array}{l}\text { Monosom. Segment } \\
\text { Monosom. Segment } \\
\text { Trisom Segment }\end{array}$ & \begin{tabular}{|l}
$7 \mathrm{q}$ \\
$\mathrm{X}$ \\
$21 \mathrm{q}$ \\
\end{tabular} & $\begin{array}{l}\text { LIMz Kinasa } \\
\text { Gen. Multipl? }\end{array}$ & $\begin{array}{l}\text { Form. Sináptica } \\
\text { Desconocida }\end{array}$ \\
\hline 2 & $\begin{array}{l}\text { Desórd. Cognit. } \\
\text { Complejo }\end{array}$ & Dislexia & Locus Cuantitativo & $6 p-15 q$ & Desconocido & $\ldots$ \\
\hline 3 & $\begin{array}{l}\text { Retardo Mental } \\
\text { Sindrómico }\end{array}$ & $\begin{array}{l}\text { Sínd. X Frágil } \\
\text { (FRAXA) }\end{array}$ & Mutación gen aislado & Xq 27.3 & $\begin{array}{l}\mathrm{FMR}_{1} \\
\text { (FMRP Ausente) }\end{array}$ & Desconocida \\
\hline 4 & $\begin{array}{l}\text { Retardo Mental } \\
\text { No específico }\end{array}$ & $\begin{array}{l}\text { Retardo Mental } \\
\text { (XLMR) }\end{array}$ & Gen aislado & $\mathrm{Xq}$ & $\begin{array}{l}\mathrm{FMR}_{1} \\
\text { Oligofrenin }\end{array}$ & $\begin{array}{l}\text { Señales de } \\
\text { GT Pase Rho }\end{array}$ \\
\hline 5 & Demencias & $\begin{array}{l}\text { Enf. Alzheimer } \\
\text { Enf. Alzheimer Precoz } \\
\text { Fronto Tempor. (Pick) } \\
\text { Enf. Huntington }\end{array}$ & $\begin{array}{l}\text { Gen aislado } \\
\text { Gen aislado } \\
\text { Mutac. Gen aislado } \\
\text { Gen aislado }\end{array}$ & $\begin{array}{l}21 q \\
14 q \\
17 q \\
4 p\end{array}$ & $\begin{array}{l}\text { Precur. Pr. Amiloide } \\
\text { (Alfas Synucleina) } \\
\text { Presenilina } 1 \\
\text { Tau } \\
\text { Huntington }\end{array}$ & $\begin{array}{l}\text { Comp. Amiloide } \\
\text { Trasp. APP } \\
\text { Prot. Asoc. Microtubul. } \\
\text { Desconocida }\end{array}$ \\
\hline
\end{tabular}

monosomía (falta un cromosoma en un par) y trisomía (un cromosoma dividido en dos). El síndrome de Williams se caracteriza por una facies característica y un defecto cardíaco (Estenosis aórtica supravalvular y pulmonar periférica); estos niños comparados en los Downs tienen una discrepancia entre el cuociente intelectual (CI) de performance y el verbal, tienen habilidades visuoperceptuales disminuidas pero preservadas las sintaxis y lexicales; además, hiperactividad, inadecuada interacción social, hiperacusia y disturbios del sueño. El síndrome de Turner, aunque no presenta retardo mental, las niñas tienen CI dismi- nuido, habilidades espaciales y matemáticas deficitarias, además, aquellos que derivaron del cromosoma X paterno (diferenciación por técnicas moleculares en cromosomas $\mathrm{X}$ materno y paterno), en comparación con las del cromosoma X materno, presentaron el estudio de "cognición social" con puntajes superiores similares a niñas normales. El síndrome de Down, conocido por una facies "mongolita", retardo mental, anomalías cardíacas y del tubo digestivo, ha sido en los últimos años, estudiado por sus relaciones bioquímicas y clínicas con la Enfermedad de Alzheimer. En su locus 21q tienen una anormal proteína precursora amiloide, el 
DNA de los telometros* disminuido tempranamente, lo cual caracteriza un estado de envejecimiento prematuro en estos niños, disturbios de la función colinérgica, demencia progresiva con cambios severos de la conducta en pacientes Down después de los 35 años asociados con neuropatología similar al Alzheimer, en fin, de modo alternativo, familias portadores de síndrome de Down y enfermedad de Alzheimer. (H. M. Eventuis).

En el segundo grupo. Están los pacientes que presentan desórdenes cognitivos complejos, tal es el caso de la dislexia, alteraciones específicas del lenguaje, discrepancia del CI verbal y no verbal, deficiencia en el reconocimiento de fonemas en la lectura de "palabras falsas", y aun en palabras simples, sin embargo, la medida general de inteligencia no está afectada. Los estudios genéticos confirman la localización del defecto de la lectura en el cromosoma 6 p21.3, sin embargo, el fenotipo de la lectura de palabras aisladas está asociada a un marcador en el cromosoma 15q 7 el "tomar conocimiento" de un fonema en el cromosoma 6p (Grigorenko y col.). En este grupo, sin localización genética demostrada por constituir desórdenes cognitivas complejos, podría adscribirse la tartamudezy el autismo. En el primero, por MRI volumétrica se han demostrado anomalías anatómicas en las áreas del lenguaje perisilvianas, sin observarse asimetría fisiológica del planum temporal, (Foundas y col.). En el segundo por MRI funcional y estudios neuropatológicos, las alteraciones en el proceso cognitivo ejecutivo (memoria espacial) se han asociado a disturbios en circuitos - menor activaciónprefrontales y singulares posteriores así como a defectos estructurales de las minicolumnas en los lóbulos frontales y temporales (Casanova y col., Luna y col.). La tartamudezy el autismo pueden considerarse también desórdenes cognitivos complejos al comprometer la expresión -emisión-del lenguaje en el primero y la comunicación y la interacción social con repertorio restringido de actividades e intereses en el segundo. Aunque la tartamudez y el autismo no están directamente en relación con material genético, debe recordarse que ambos tienen comorbilidad genética con el síndrome de ADHD, Tourette y el desorden obsesivo compulsivo mediante los receptores de dopamina $\left(\mathrm{DA}_{2}\right)$.

En el tercer grupo. Se presenta los pacientes con retardo mental sindrómico, tomando como arquetipo el síndrome de $\mathrm{X}$ frágil, caracterizado, desde 1991 por un fenómeno de expansión que repite un trinucleotido anormal en un locus del brazo largo del cromosoma X (mutación de un gen aislado). En este síndrome, descrito por Aníbal Escalante por primera vez en el Perú (1985), aparece un niño con orejas grandes y alargadas "Tipo Dumbo" cara alargada, prognatismo, macrocefalia, conducta hiperactiva, retardo del lenguaje, algunos rasgos autistas y articulaciones con mayor extensibilidad. Tienen prolapso mitral, dilatación de la aorta ascendente, macroorquidismo. Una proporción de ellos tiene epilepsia. Las niñas exhiben retardo mental leve con problemas de aprendizaje y conducta, déficit de aprendizaje social y menopausia

\footnotetext{
* Las alteraciones cromosomiales que incluyen la protección de los telometros, bloquean el ciclo regulatorio celular de algunas proteínas, como la p53, resultando en una inmortalización celular y activación de los oncogen celulares determinando in vitro e in vivo la ruta para una incontrolable división celular -inmortalización celular-y por ende un tumor. Los gliomas cerebrales humanos demuestran altas concentraciones de telomerasa, mutación del gen de la p53 inactivando el rol supresor del tumor, mediante su adhesión a la proteína T. (E.O. Major).
} 
precoz. La mutación del gen $\mathrm{FMR}_{1}$ determina la ausencia de la proteína FMRP que se encuentra en la mayoría de las neuronas y probablemente controla el producto de los genes, sin embargo, no se conoce la relación entre su ausencia y el déficit cognitivo.

En el cuarto grupo. Se toma en cuenta, los pacientes con retardo mental no específico que pertenecen a varios grupos familiares en los cuales, se identifican genes aislados cuyas mutaciones se manifiestan en los "productos" bioquímicos que determinan ruptura de las conexiones axonales, deficiencia en el desarrollo cortical y alteraciones en la liberación de neurotrasmisores sinápticos, todo lo cual, afecta las neuronas comprometidas en los sistemas cognitivos. Entre los productos anormales del gen en el cromosoma Xq está la oligofrenia que codifica la proteína rhoGAP que estimula la actividad intrínseca GT Pase de las pequeñas proteínas $\mathrm{G}$ tales como Rho, Rac, y $\mathrm{Cdc} 42$, las cuales intervienen en la formación de las dendritas y laminación crotical.

Es interesante señalar la correlación genética en familias con XLMR que afecta fundamentalmente al sexo masculino y el síndrome del RETT, desorden neurológico progresivo que afecta exclusivamente al sexo femenino. En 1999 (Amirre y col.) describieron mutaciones en la proteína 2 unida al metil $\mathrm{CpG}\left(\mathrm{MECP}_{2}\right)$ en un gen mapeado sobre el cromosoma Xq28 en pacientes portadores de síndrome de RETT. En el $25 \%$ de mujeres con clásico RETT no se encontraron mutaciones MECP2; sin embargo, mutaciones MECP2 han sido descritas en mujeres sin el fenotipo clásico. De otro lado, las mutaciones del MECP2 en hombres descritas en un alto porcentaje del paciente con el síndrome de RETT clásico, resultaron en una sobrevivencia no mayor de 1 año o se consideraron letales. Dotti y col. han reportado 6 miembros de una familia italiana con portadores de retardo mental ligado al cromosoma X (XLMR), los cuales presentaron un tipo de mutación A $17 \mathrm{OV} \mathrm{MEC}_{2}$. El estudio clínico demostró que la alteración neurológica lenta y progresiva fue más severa en los hombres que en las mujeres, sin embargo, las mutaciones de $\mathrm{MECP}_{2}$ no fueron siempre letales en el sexo masculino.

En el quinto grupo. Se presentan los desórdenes neurodegenerativos que incluyen las demencias cortical y subcortical determinadas por genes anormales, sea por mutación o división. En estos desórdenes cognitivos el gen aislado mutante tiene un producto bioquímico que deteriora la función neural a nivel del flujo axoplásmico en las proteínas precursoras y en la expresión de múltiples neurotrasmisores, todo lo cual, vía apoptosis resulta en la muerte neuronal. La mutación anormal del gen del cromosoma $21 \mathrm{q}$, determina lesiones sinápticas asociadas al disturbio de la ALFA sinucleína (proteína importante en la plasticidad neuronal) precursora del componente amiloide (NACP) de las placas neuríticas que se presentan en el cerebro de la demencia tipo Alzheimer y en los cuerpos de Lewy de la enfermedad de Parkinson familiar. La alfa sinucleína es similar a la synelfina, una proteína localizada en el cerebro de una variedad de canario trinador ("Zebra Finch") que es responsable de la maduración, "memorias" y "vocalización" del trino de canario macho.

La mutación anormal del gen del cromosoma $14 \mathrm{q}$ está asociada a la perturbación de la presenilina 1 localizada en la región postsináptica indispensable en la embriogénesis normal del sistema nervioso central y en el transporte de la apolipoproteína (APP). Aunque el envejecimiento es un factor de riesgo en el desarrollo de la enfermedad de Alzheimer, en el caso del 
disturbio de las presenilinas el proceso demencial aparece en pacientes jóvenes. Es posible que un grupo significativo de familias -alrededor de 4,000 personas- fueron portadores y desarrollaron esta enfermedad en varios pueblos de Antioquía (Medellín, Colombia). Justamente, en uno de ellos, Yarumal, la observación de un literato visitante-Gabriel García Marquez-trasladó a la ficción la historia de la familia de Aureliano Buendía en "Macondo" y escribió "Cien Años de Soledad" (Beteta).

Las mutaciones que comprometen el gen de la proteína TAU en el cromosoma $17 \mathrm{q}$ son responsables de muerte neuronal en la patología molecular. El cuadro clínico comienza con cambios del carácter y disturbios de la personalidad y progresivamente se desarrolla la declinación del proceso cognitivo en la demencia fronto temporal (atrofia de Pick) asociada a Parkinsonismo. En este caso, el disturbio del proceso cognitivo secundario al proceso bioquímico patológico no sólo compromete las funciones cognitivas, también la personalidad y el control del movimiento automático, lo cual implica diferentes vías y sistemas neuronales.

Por último, en este grupo la mutación del gen Huntingtin en el cromosoma 4p63 determina la enfermedad de Huntington, desorden autosomo dominante que origina un disturbio neurodegenerativo progresivo caracterizado clínicamente por declinación de las funciones cognitivas y un cuadro severo de movimientos involuntarios asociado a transtornos del tono muscular. El proceso genético exhibe repeticiones de trinucleótido (CAG) de modo inestable encontrándose el fenómeno de anticipación (triplete que se amplifica de modo progresivo en un modelo no mendeliano, por el cual el inicio del cuadro clínico es cada vez más precoz y más grave) especialmente en la transmisión padre-hijo. La deficiencia de las funciones cognitivas no tienen una clara explicación, sin embargo, la observación de inclusiones intranucleares e intraneurales de Huntingtin en estructuras subcorticales y el disturbio en la expresión de múltiples neurotransmisores (por el análisis del ratón transgénico) podría originar severos defectos en las redes neuronales córtico-subcorticales que subtienden sistemas cognitivos y circuitos fronto-estrio-mesolímbicos. A propósito de enfermedad de Huntington, en nuestro medio deben revisarse los aportes de J.M. Cuba, C. Cosentino y P. Mazzetti.

Al final de esta revisión de neurogenética en funciones cognitivas, se han discutido desórdenes genéticos responsables de variantes de retardo mental. Desórdenes cognitivos complejos y variadas formas de demencia. Desde el punto de vista clínico, la cognición ha sido representada por deficiencia de la inteligencia, disturbios de lenguaje, déficit de la memoria, alteraciones de conducta y desórdenes de la personalidad. Es muy difícil buscar unidad clínica y el término cognición se ha referido a sistemas cognitivos-intelectuales. En la práctica clínica, los desórdenes pertenecen a la neuropsiquiatría y justamente los estudios genéticos, demuestran la interrelación no sólo en la genealogía de estos pacientes (esquizofrénicos con familiares portadores de retardo mental y algún tipo de demencia) sino en las variantes muy cercanas del cuadro clínico, especialmente en la evolución y progresión de la enfermedad.

La genética clínica aproxima mucho la demencia, la enfermedad bipolar y la esquizofrenia. Graf y col. han estudiado el síndrome de delección (pérdida en una parte del cromosoma) en el cromosoma 22q11.2, en el cual se pierden más de 30 genes, uno de los cuales es el gen de la Catecol-Ometiltransferasa (COMT), enzima que inac- 
tiva por O-metilación los neurotrasmisores catecolaminas (DA, EP y NE). Las manifestaciones clínicas incluyen moderadas alteraciones de la atención, concentración, interacción de funciones sociales-emocionales, sin embargo, algunos niños y adolescentes presentan marcada ansiedad, terrores nocturnos, variaciones del temperamento, desorden obsesivo-compulsivo, desorden bipolar y un cuadro alucinatorio. El cuadro clínico incluye numerosas alteraciones estructurales (síndrome velocardiofacial de Digeorge), problemas de aprendizaje tipo síndrome de ADHD y pobre socialización en la niñez, depresión en la pubertad, esquizofrenia y desorden bipolar en la adultez. Los avances en genética molecular en la proximidad de este defecto en 22 q11.2 han demostrado un desorden bipolar asociado a catatonía en un eslabonamiento de mutación en el cromosoma 22q13 y cuadros de esquizofrenia catatónica en mutaciones de los cromosomas 22q10, 22q13.33 y 15q15.

Los últimos estudios de eslabonamiento genético entre la enfermedad de Alzheimer y la psicosis, han sido presentados por Bacanu y col. basados en la incidencia de $40-60 \%$ de alucinaciones y delusiones en los pacientes con enfermedad de Alzheimer de comienzo tardío. El análisis de eslabonamiento de las familias con Alzheimer tardío y la psicosis, es sugestivo de una "ligazón" etiológica. Los estudios de "ligación" del genoma estudiado en el Instituto Nacional de Salud Mental de pacientes con Enfermedad de Alzheimer, han demostrado que los pacientes con psicosis y demencia presentan "ligazón" en locus de 3 cromosomas 2,6 y 21 , todo lo cual sugiere que los estudios que relacionan Alzheimer tardío y cuadros de psicosis, deben continuar, para demostrar definitivamente la interrelación genética entre la demencia de Alzheimer y la psicosis esquizofrénica.

El estudio de las variantes genéticas que determinan disturbios de los sistemas cognitivos, es interesante porque, descubre nuevas aproximaciones de bioquímica molecular en la interpretación de las enfermedades neuropsiquiátricas, sin embargo, estamos lejos todavía para establecer las bases genéticas de las funciones cognitivas. Los estudios de mutaciones de ingeniería genética en ratones para descubrir modelos de aprendizaje y memoria, así como la investigación del material genético en los miembros de familias portadoras de disturbios cognitivos, puede seguir siendo de gran utilidad. De todos modos, la ciencia sigue avanzando y los clínicos seguimos aprendiendo y descubriendo muchos misterios de la neurobiología. 


\section{BIBLIOGRAFÍA}

1. Amir, RE et al. Rett Syndrome is caused by mutations in X-linked MECP2, encoding methye-CpG-bincling protein 2. Nat. Genet, 1999; 23:185-188.

2. Bacanu, S.A.et al. Linkaje Analysis of Alzheimer Disease with Psychosis. Neurology. 2002; 59:118-120.

3. Beteta E. Neurobiología y Neurogenética, 1999; Rev. Per. Neurol 5:75-79.

4. Casanova; M.F.et al. Minicolumnar Pathology in Autism. Neurology 2002; 58:428-432.

5. Cosentino C., Ortega, O. Enfermedad de Huntington y edad de inicio XVIII Congreso Peruano de Neurología, Lima, 2001.

6. Cuba J.M., Castro C., Benzaquen, M. Sobre la Epidemiología de la Corea de Huntington en el Perú. Rev. NeuroPsiquiatría, 1983; 46(3-4):1-7.

7. Dotti, M.T. et al. A Rett Syndrome MECP2 mutation that causes mental retardation in men. Neurology 2002; 58:226-230.

8. Escalante, A. Escalante Syndrome at mark X chromosome. Am. J. Med. Gen. 1982;12,2:237-240.

9. Evans G. D. The Human Genome Project. Aplications in the diagnosis and treatment of Neurologic disease. Arch. Neurol. 1988; 55:1287-1290.

10. Evenhuis, H.M. The Natural History of Dementia in Down Syndrome. Arc. Neurol. 1990; 47:263-267.
11. Flint Jonathan. The Genetic Basis of Cognition. Brain. 1999; 122:295-303.

12. Foundas. A.L. et al. Anomalous Anatomy of Speech-Language Areas in Adults with persistent developmental stuttering. Neurology. 2001; 57:207215.

13. Gabor-Mikolos G.L. \& Rubin J.M. The rol of the genoma project in determining gene function: Insights from models organisms. Cell. 1996; 86:521529.

14. Grigorenko, E.L. et al. Susceptibility loci for distinct components of development dyslexia on cromosomes 6 and 14 A.M.J. Hum Genet. 1997; 60:27-39.

15. Graf, W.D. et al. Catecholamines in patients with 22q11.2 deletion syndrome and the low-activity COMT polymorphism. Neurology. 2001; 57: 410-416.

16. Luna, B. et al. Neocortical System abnormalities in autism. An FMRI study of spatial working memory. Neurology. 2002; 59:834-840.

17. Major, Eugene O. From Telemeres To... Antigens: Many Roadas... Multiple Pathways... Novel Associations in the search for the origins of human gliomas. Annals of Neurology. 2000; 48,6:823-825.

18. Mazzetti, Pilar. Anticipación. Concepto clínico. Mesa Redonda: Neurogenética, Tripletes repetidos y anticipación. XVIII Congreso Peruano de Neurología, Lima, 2001. 
19. McHugh T.J. et al. Impaired hippcampal representation of space in CA1SPECIFIC NMDAR1 Knockout mice. Cell: 1996; 87:1339-1349.

20. McKusik, VA. Mendelian inheritance in man: catalogs of autosomal dominant autosomal recessive and $\mathrm{X}$ linked phenotypes $9^{\text {th }}$ ed. Johns Hopkins University Press, Baltimore. 1990.

21. Rotenberg et al. Mice expressing activated CaMK lack low frecuency LTP and do not form stable place cells in the CA1 region of the hippocampus. Cell 1996; 87:1147-1148. (Comments). 